\title{
STUDY ON THE RELATION BETWEEN SELF CONSISTENCY AND CONGRUENCE AND MENTAL HEALTH OF POSTGRADUATES
}

\author{
Liu Chuanlei ${ }^{1 *}$, Han Yuanfei ${ }^{1}$ Li Guomin ${ }^{2}$

\begin{abstract}
1 Heilongjiang Bayi Agricultural University, Heilongjiang Daqing,163319, China.
${ }^{2}$ Nanjing Normal University of Special Education, Jiangsu Nanjing,320100, China.

*Corresponding Author Email: 312332575@qq.com
\end{abstract}

This is an open access article distributed under the Creative Commons Attribution License, which permits unrestricted use, distribution, and reproduction in any medium, provided the original work is properly cited.

\begin{tabular}{|c|c|}
\hline ARTICLE DETAILS & ABSTRACT \\
\hline Article History: & $\begin{array}{l}\text { Reveal the Relation between Self consistency and congruence and Mental Health of Postgraduates. Adopt self- } \\
\text { consistency and congruence questionnaire, mental health questionnaire to carry out questionnaire investigation on }\end{array}$ \\
\hline Received 12 November 2017 & 500 postgraduates of four Nanjing colleges and universities. Mental health of postgraduates has extremely negative \\
\hline Accepted 12 December 2017 & notable relevance with the disharmony of oneself and experience and it has extremely negative notable relevance with \\
\hline Available online 1 January 2018 & $\begin{array}{l}\text { self-flexibility. The degree of self consistency and congruence and self-flexibility of postgraduates with better } \\
\text { psychological health situation is higher than that of postgraduates with poor mental health situation. Disharmony of } \\
\text { oneself and experience, flexibility function of oneself forecast mentality symptom dissociation amounts to a certain } \\
\text { extent. The degree of self-consistency and congruence has a significant influence on mental health. }\end{array}$ \\
\hline
\end{tabular}

\section{KEYWORDS}

Postgraduates, self-consistency and congruence, mental health.

\section{INTRODUCTION}

The government has implemented the expansion policy of postgraduates' enrollment since the 1990s. The number of China's postgraduate increases progressively at the speed of almost $21 \%$ every year. According to the latest release of the Ministry of Education National Education Development Statistics Bulletin data, in 2016, there are totally 200.4 million postgraduates at school, 55.2 million fresh graduates, and 64.5 million recruit students [1]. Postgraduates have become a group that can not be ignored in higher education. Postgraduates are a group that goes along with the deep reform of China's social development and an important group that enhances China's comprehensive national strength and international competitiveness. Paying attention to their psychological health is the call of the times and the need of the future.

Self consistency and congruence is a hot topic for the psychologists in the research of adolescent psychology. Scholars at home and abroad pay much attention to the research in this field and launch a lot of discussion on this issue. Self consistency and congruence is one of the most important concepts in the theory of C. Rogers's personality. It refers to self's internal coordination and the coordination between the self and the experience. C. Rogers believes that individuals have the function of maintaining consistency of various self perceptions coordinating the relation between self and experience. If there appear conflicts among various self perceptions or contradictions between self and experience, individuals will experience inner tension and turbulence. In order to maintain the unity of self consistency and congruence, the individual will take a variety of defense responses, so as to provide the possibility of psychological barriers [2]. So, the self harmony of the individual has a very close relationship with mental health. Therefore, in this study, the author tries to reveal the relationship between postgraduates' mental health and self consistency and congruence and offer help to mental health education for postgraduates.

\section{RESEARCH METHODS}

\subsection{Research Instruments}

\subsubsection{Mental Health Questionnaire}

Symptom checklist 90, SCL-90 is compiled by Derogatis in 1979, translated by Wang Zhengyu [3]. The scale has 90 items that are divided into somatization, obsessive-compulsive symptoms, interpersonal sensitivity, depression, anxiety, hostility, terror, paranoia, mental illness and other 10 factors. Each entry uses a 1 5 score.

\subsubsection{Self-Consistency and Congruence Questionnaire}

The author uses the Self Consistency and Congruence Scale (SCCS), which was compiled by Wang Dengfeng who bases on the concept of self consistency and congruence of Rogers [4]. There is a total of 35 items, including 3 components: disharmony of self and experience, self flexibility, self stereotype. The disharmony between self and experience includes self evaluation on ability and emotion, self consistency and sense of helplessness, which mainly reflect the unreasonable expectations of experience. Self stereotype mainly reflects the individual's inflexibility and rigidity and cannot make certain changes according to the changes of things. Self flexibility is the opposite of self stereotype. SCCS uses five grade scoring system. After the test of college students, the scale has a high degree of homogeneity reliability and predictive validity.

\subsection{Samples}

First and third year master's students in Nanjing Normal University, Hehai University, Nanjing University of Science and Technology and Medicine School of Southeast University are chosen as subjects. Using the postgraduates' mental health questionnaire and self consistency and congruence questionnaire, 500 questionnaires were distributed, 427 questionnaires were recovered, and the recovery rate was $85.4 \%$. Among them, 375 valid questionnaires were received. The test case is shown in the following Table 1:

Table 1: Sample Distribution of Postgraduates

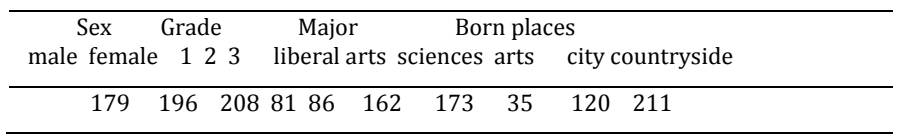

\subsection{Procedures}

The author or his classmates who major in psychology carry out group test 
on the students in the dormitory as a unit and give the necessary explanation on questionnaire instructions to the tested students. Test time is about 10 minutes. At the end of the test, the questionnaires are collected, and data collection time is April 2016. The author uses SPSS19.0 for data processing, statistical analysis.

\section{RESULTS}

3.1 Correlation Analysis of Self Consistency and Congruence and Mental Health of Postgraduates

Table 2: Person Correlation Analysis of Self Consistency and Congruence and Mental Health Disharmony of self and experience Self Stereotype Self flexibility

\begin{tabular}{llll} 
Somatization & $0.352^{* *}$ & $0.472^{* *}$ & $-0.519^{* *}$ \\
Obsessive-compulsive & $0.505^{* *}$ & $0.310^{* *}$ & $-0.227^{* *}$ \\
Interpersonal sensitivity & $0.481^{* *}$ & 0.241 & -0.208 \\
Depression & $0.487^{* *}$ & 0.301 & $-0.243^{* *}$ \\
Anxiety & $0.601^{* *}$ & 0.215 & -0.107 \\
Hostility & $0.436^{* *}$ & $0.139^{*}$ & $-0.177^{*}$ \\
Terror & $0.417^{* *}$ & 0.142 & -0.153 \\
Paranoia & $0.361^{* *}$ & 0.092 & -0.147 \\
Mental illness & $0.415^{* *}$ & 0.104 & -0.135 \\
Total average & $0.547^{* *}$ & $0.371^{* *}$ & $-0.503^{* *}$ \\
\hline
\end{tabular}

Note: * indicates a significant level at $0.05, * *$ indicates a significant level at 0.01 , the same below.

Table 2 shows that: disharmony of self and experience shows extremely significant positive correlation with every symptom factor and total score of SCL-90; self flexibility, self rigidity and somatization, total score of SCL90 show extremely significant negative correlation, and they show very significant negative correlation with obsessive-compulsive symptoms and depression, and a significant negative correlation with hostility.

\subsection{The Regression Analysis of Self Consistency and Congruence and Mental Health of Postgraduates}

Table 3: The Regression Analysis of Self Consistency and Congruence and Mental Health of Postgraduates
According to the result of correlated analysis of the above table, in order to further understand how much the individual self harmony can predict mental health variance, factors of mental health are taken as dependent variable, self consistency and congruence dimensions are taken as the independent variable, regression analysis is carried out step by step.

\section{$\begin{array}{lllll}\text { Entering equation variable } & \text { Beta } & \mathrm{T} & \mathrm{F} & \mathrm{R}^{2}\end{array}$}

Somatization
Obsessive-compulsive
Interpersonal sensitivity
Depression
Anxiety
Hostility
Terror
Paranoia
Mental illness
Total average

Table 3 shows that taken total score of SCL-90 as dependent variable in the regression analysis, entering equation variables are disharmony of self and experience, self flexibility successively, both of which can predict $32 \%$ of the variance in psychological symptoms; taken somatization as dependent variable in the regression analysis, entering equation variables are self flexibility, disharmony of self and experience successively, both of which can predict $29.5 \%$ of the variance in somatization symptoms; taken other factors as the independent variable in the regression analysis, entering equation variable is only the dimension of disharmony of self and experience, the amount of variation of predicting dependent variable of this dimension is $12.6 \%-33.5 \%$ ranging.

\section{DISCUSSION}

The research result of the relation of disharmony of self consistency and congruence and mental health shows that disharmony of self consistency and congruence shows extremely significant positive correlation with every symptom factor and SCL-90 quantity score, and the prediction ability for their variability amount can reach $36.2 \%$, The degree of self consistency and congruence and self-flexibility of postgraduates with better psychological health situation is higher than that of postgraduates with poor mental health situation, which shows that the relation of psychological problems and disharmony of self consistency and congruence is very close. Self disharmony contains two aspects: one is the disharmony of self and experience, the other is the disharmony of internal self. Rodgers believes that individuals have the ability to maintain self consistency, tend to determine the principles of action in accordance with the self concept, and only allow the experience that fits self concept. Once encountered with experience that contradicts the self concept, the individual will be afraid of his usual self concept being destroyed and feel

$\begin{array}{llll}0.224 & 3.106^{* *} & 35.184^{* *} & 0.295 \\ -0.468 & -6.529^{* *} & & \\ 0.589 & 9.237^{* *} & 82.527^{* *} & 0.335 \\ 0.479 & 6.781^{* *} & 44.251^{* *} & 0.212 \\ 0.586 & 8.870^{* *} & 81.602^{* *} & 0.285 \\ 0.525 & 7.513^{* *} & 56.016^{* *} & 0.301 \\ 0.466 & 6.512^{* *} & 41.527^{* *} & 0.227 \\ 0.457 & 6.014^{* *} & 37.502^{* *} & 0.189 \\ 0.319 & 4.261^{* *} & 18.355^{* *} & 0.126 \\ 0.413 & 5.542^{* *} & 19.843^{* *} & 0.158 \\ 0.450 & 6.502^{* *} & 41.520^{* *} & 0.320 \\ -0.316 & -4.437^{* *} & & \end{array}$

threatened. Because a portion of the postgraduate's lack objective and comprehensive understanding of self and cannot hold correct concepts of self, under the outside stimulation, they are easy to encounter experiences that are inconsistent with self-concept. At this time, they will take some defense mechanisms to ensure the original self concept, through which to avoid changing self concept and causing mental suffering. But excessive use of passive defense mechanism will lead to the generation of poor adaptation and psychological barriers.

The development of self consciousness and the establishment of ego identity are important tasks in the early stage of adulthood. Factors that affect self - consciousness include the experience of early childhood, the attitudes towards others, and the evaluation of others, independent consciousness and their role in society, status and identity, etc. [5]. With the rapid development of postgraduates' sense of self, subjective self and objective self appear and the ideal self, social self and real self differentiate. But self development is not fully synchronous, and sometimes there will appear the phenomenon of imbalance and disunity. First of all, in the self understanding, the self subjective of postgraduates tend to be higher than the objective self, resulting in arrogance. Expectations of society, family and themselves are very high, but the employment reality is cruel and the original employment momentum of "The daughter of an emperor does not worry about finding a husband" is accounted with an unprecedented impact and challenges. Secondly, in terms of self emotion, the postgraduates have a strong self-esteem; hope to get the attention and respect of others. But the attitude of others does not necessarily meet the requirements of the subjective. In addition, in self-control, the world is full of temptations and utilitarian, and the postgraduates face huge pressure of employment, academics, economy, and achievement need, so sometimes they are not very good at dealing with things, coordinating the 
contradiction, controlling and regulating themselves [6]. Self-conscious contradiction is not only reflected in the self understanding, self experience and internal self-control, but also in the relationship between the three. When the individual is not consistent with the self in understanding of cognizance, emotion, and will, there will appear the behavior of confusion and conflict. A variety of self can not be coordinated, which will lead to that self concept is difficult to form, self-image can not be established, the individual's inner conflict, anxiety, pain and anxiety appear, affecting the individual's physical and mental health.

Self flexibility has negative correlation with total score, somatization, obsessive compulsive symptoms, depression, hostility, and the selfflexibility of postgraduates with better psychological health situation is higher than that of postgraduates with poor mental health situation. The main reason is that the individuals with a low self flexibility, the point view of thinking is often single. And in interpersonal relationships, because they won't stand from other people's point of view on the issue, do not put themselves in the places for the sake of others, so it is often easy to cause the interpersonal tensions. Each part of their self is more difficult to harmonize and due to the stereotype of self-concept and rigidity, their attitude of treating things is rigid. There will be more experiences that are not consistent with self concept; it is more frequent to produce inner contradictions and conflicts. So, it provides the possibility for the psychological barrier and the physical and psychological symptoms.

This study tells that we should pay attention to the mental health and self harmony of postgraduates. From the society, school, family and themselves, postgraduates should know, evaluate, please, control themselves correctly.

\section{Acknowledgements}

The achievements of the key research project (project number: DSGB2016010) of the 2016 daqing philosophy and social science program ; Heilongjiang provincial funding project of August first land reclamation university(XRW2017-10) ; Heilongjiang youth education scientific planning subject(GBD1317068).

\section{REFERENCES}

[1] MEPRC. 2016. Statistical bulletin of the national education development in 2015[EB/OL].[2016-76].http://www.moe.gov.cn/srcsite/A03/s180/moe_633/201607/t2016 0706_270976.html

[2] Rogers, C.R. 1959. A theory of therapy, personality, and interpersonal relationship as developed in the client-centered framework. In S. Koch (Ed.). Psychology. A study of science. New York. McGraw-Hill, 184-256.

[3] MHAH. 1999. Mental health assessment handbook (Revised Edition), 314.

[4] Dengfeng, W. 1994. Establishment of self-harmony scale (J). Journal of clinical psychology in China, 2 (1), 19-22.

[5] Chongde, L. 2003. Developmental psychology. Beijing: People's education press, 409-418.

[6] Yulan, Y., Xifu, Z. 2005. The current situation of postgraduates' psychological stress and its related influencing factors during the enrollment expansion period. Psychological development and education, 21 (3), 99-103.

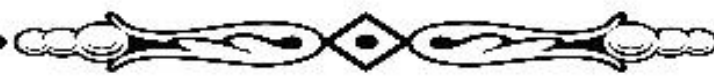

